Abstracta Iranica Abstranica

Revue bibliographique pour le domaine irano-aryen

Volume 32-33 | 2013

Comptes rendus des publications de 2009-2010

\title{
S. R. Nadjmabadi (ed.). Conceptualizing Iranian Anthropology: Past and Present Perspectives
}

\section{Yoko Suzuki}

\section{(2) OpenEdition}

1 Journals

\section{Édition électronique}

URL : http://journals.openedition.org/abstractairanica/41064

DOI : 10.4000/abstractairanica.41064

ISSN : 1961-960X

Éditeur:

CNRS (UMR 7528 Mondes iraniens et indiens), Éditions de l'IFRI

\section{Édition imprimée}

Date de publication : 1 décembre 2013

ISSN : 0240-8910

\section{Référence électronique}

Yoko Suzuki, « S. R. Nadjmabadi (ed.). Conceptualizing Iranian Anthropology: Past and Present Perspectives », Abstracta Iranica [En ligne], Volume 32-33 | 2013, document 463, mis en ligne le 01 juillet 2016, consulté le 03 octobre 2020. URL : http://journals.openedition.org/abstractairanica/41064 ; DOI : https://doi.org/10.4000/abstractairanica.41064

Ce document a été généré automatiquement le 3 octobre 2020.

Tous droits réservés 


\title{
S. R. Nadjmabadi (ed.). Conceptualizing Iranian Anthropology: Past and Present Perspectives
}

\author{
Yoko Suzuki
}

\section{RÉFÉRENCE}

S. R. Nadjmabadi (ed.). Conceptualizing Iranian Anthropology: Past and Present Perspectives. New York - Oxford, Berghahn Books, 2009, 278 p.

1 Cet ouvrage collectif est l'édition des actes d'un colloque s'est tenu du 30 septembre au 2 octobre 2004 sous le titre « Der Iran: Gesellschaft zwischen Tradition und Moderne », et qui était organisé par l'Institut für Historishe Ethnologie de l'université de Johann Wolfgang Goethe à Francfort.

2 Sept chercheurs natifs de l'Iran dont trois installés à l'étranger (en France, aux EtatsUnis et en Angleterre) et six étrangers (2 Américaines, 2 Français, 1 Anglais et 1 Allemand) ont contribué à la rédaction de l'histoire et la situation actuelle de l'anthropologie sur l'Iran ou en Iran.

3 Les articles présentés notamment dans les deux premiers chapitres révèlent que l'origine et l'évolution de l'anthropologie de l'Iran sont profondément liées à la politique du pays: sa société et sa culture furent rapportés, depuis le XIX ${ }^{\mathrm{e}}$ s., par quelques gouverneurs, voyageurs ou orientalistes étrangers, en particulier des Anglais qui venaient de l'Inde colonisé. $\mathrm{Au} \mathrm{XX}^{\mathrm{e}}$ s., grâce à l'essor général de cette discipline comme en raison de l'importance géopolitique et économique de ce pays devant la scène internationale, l'Iran attira tous les grands Etats et les enquêtes d'anthropologie y démarrèrent. Sous le régime de Mohammad Reḍā Šāh pro-américain, de nombreux anthropologues menèrent des enquêtes de terrain. Selon M. E. Hegland (p. 45), ils 
furent au nombre de 12 dans les années 1960. Cet impact scientifique étranger incita les collaborateurs iraniens sur place à poursuivre ces recherches. En même temps, la politique en faveur de l'occidentalisation provoqua une nouvelle vague d'enquêtes anthropologiques non seulement parmi les occidentaux mais aussi parmi les Iraniens qui étudiaient à l'étranger dans les années 1970 (45 étrangers et 13 Iraniens: M. E. Hegland, p. 46).

4 Après la révolution islamique, la politique du nouveau régime estima que l'anthropologie était un moyen de colonisation et les anthropologues, des espions étrangers. Certains étrangers changèrent de pays ou de domaine de recherche, alors que les difficultés des étrangers offrirent aux iraniens une belle occasion de combler cette lacune scientifique, car ils ont en gros deux avantages, administratif et socioculturel, pour mener rapidement des enquêtes de terrain. Malgré une réévaluation des enquêtes de terrain après la guerre contre l'Iraq, notamment depuis la présidence de Hātamī, la présence des anthropologues étrangers est toujours très limitée en Iran. De surcroît, les sujets et les objets de recherche restent restreints sous le contrôle des autorités.

5 Si elle a été politisée dans son origine et sa progression, l'anthropologie sur l'Iran a créé un clivage entre les représentants des sociétés observatrices et ceux de la société observée, soit entre les exportateurs et les importateurs de l'étude. La différence de situation a laissé certainement un écart dans la vision notamment entre les anthropologues iraniens et les confrères étrangers.

6 Par conséquent, sans chercher un terrain d'entente ni une réévaluation de cette étude relativement aux autres disciplines telles que l'archéologie, la sociologie et l'histoire, cet ouvrage présente, en ce qui concerne la "conceptualisation", une cacophonie d'arguments qui nous rend sceptiques sur l'intérêt scientifique de ce type de débat, malgré son apport dans l'histoire de l'anthropologie.

7 Voici la liste des articles :

8 I- From Folklore to Anthropology: The Passage

9 - A. A. Bulookbashi, « The contribution of foreign anthropologists to Iranology »;

10 - U. Marzolph, "Storytelling as a constituent of popular culture: Folk narrative research in contemporary Iran »;

11 - M. E. Hegland, «Iranian anthropology- crossing boundaries: Influences of modernization, social transformation and globalization ». anthropology in Iran »;

\section{II- Voices From Within: Institutions and Professions}

- N. Fazeli, « Anthropology in postrevolutionary Iran »;

- N. Fakouhi, « Making and remaking an academic tradition: Towards an indigenous - S. Shahshahani, « Iranian anthropologists are women ».

\section{III- Anthropological Practice: Constraints and Possibilities}

- J.-P. Digard, « Applied anthropology in Iran?» ;

- M. Shahbazi, «Past experiences and future perspectives of an indigenous anthropologist on anthropological work in Iran »;

9 - L. Beck, « Anthropological research in Iran »;

- Z. Mir-Hosseini, « Being from there: Dilemmas of a 'native anthropologist' ». 
21 IV- Past and Present Perspectives: Challenging the Future

22 - C. Bromberger, « Usual topics: Taboo themes and new objects in Iranian anthropology ";

23 - A. Fariba, «Islamophobia and malaise in anthropology »;

24 - R. Tapper, « Personal reflections on anthropology of and in Iran »

\section{AUTEURS}

YOKO SUZUKI

Paris 